\title{
Ballistic Experiments with Titanium and Aluminum Targets
}

\author{
R.P. Gogolewski and B.R. Morgan
}

\section{November 23, 1999}

Lawrence Livermore National Laboratory 


\section{DISCLAIMER}

This document was prepared as an account of work sponsored by an agency of the United States Government. Neither the United States Government nor the University of California nor any of their employees, makes any warranty, express or implied, or assumes any legal liability or responsibility for the accuracy, completeness, or usefulness of any information, apparatus, product, or process disclosed, or represents that its use would not infringe privately owned rights. Reference herein to any specific commercial product, process, or service by trade name, trademark, manufacturer, or otherwise, does not necessarily constitute or imply its endorsement, recommendation, or favoring by the United States Government or the University of California. The views and opinions of authors expressed herein do not necessarily state or reflect those of the United States Government or the University of California, and shall not be used for advertising or product endorsement purposes.

Work performed under the auspices of the U. S. Department of Energy by the University of California Lawrence Livermore National Laboratory under Contract W-7405-Eng-48.

This report has been reproduced directly from the best available copy.

Available to DOE and DOE contractors from the Office of Scientific and Technical Information

P.O. Box 62, Oak Ridge, TN 37831

Prices available from (423) 576-8401

http://apollo.osti.gov/bridge/

Available to the public from the National Technical Information Service

U.S. Department of Commerce 5285 Port Royal Rd., Springfield, VA 22161 http://www.ntis.gov/

OR

Lawrence Livermore National Laboratory

Technical Information Department's Digital I ibrary http://www.llnl.gov/tid/Library.html 


\title{
Ballistic Experiments \\ With \\ Titanium and Aluminum Targets
}

\author{
by \\ Raymond P. Gogolewski \\ and \\ Bruce R. Morgan
}

\section{Introduction}

During the course of the project we conducted two sets of fundamental experiments in penetration mechanics in the LLNL Terminal Ballistics Laboratory of the Physics Directorate. The first set of full-scale experiments was conducted with a $14.5 \mathrm{~mm}$ air propelled launcher. The object of the experiments was to determine the ballistic limit speed of $6 \mathrm{Al}-4 \mathrm{~V}$-alloy titanium, low fineness ratio projectiles centrally impacting 2024-T3 alloy aluminum flat plates and the failure modes of the projectiles and the targets. The second set of one-third scale experiments was conducted with a $14.5 \mathrm{~mm}$ powder launcher. The object of these experiments was to determine the ballistic limit speed of $6 \mathrm{Al}-4 \mathrm{~V}$ alloy titanium high fineness ratio projectiles centrally impacting $6 \mathrm{Al}-4 \mathrm{~V}$ alloy titanium flat plates and the failure modes of the projectiles and the target.

We employed radiography to observe a projectile just before and after interaction with a target plate. Early on, we employed a non-damaging "soft-catch" technique to capture projectiles after they perforated targets. Once we realized that a projectile was not damaged during interaction with a target, we used a 4-inch thick 6061-T6-alloy aluminum witness block with a 6.0-inch x 6.0-inch cross-section to measure projectile residual penetration. We have recorded and tabulated below projectile impact speed, projectile residual (post-impact) speed, projectile failure mode, target failure mode, and pertinent comments for the experiments. The ballistic techniques employed for the experiments are similar to those employed in an earlier study $(\operatorname{Ref} 1)$.

\section{Titanium Projectiles and Aluminum Plate Targets}

\section{Launch and Measurement Techniques}

In order to launch projectiles of very low mass at repeatable speeds (under the same launch conditions) from our standard $14.5 \mathrm{~mm}$ single-stage, powder gun, we modified the breech mechanism. Because the projectile speed range of interest was $200 \mathrm{fps}$ to $1000 \mathrm{fps}$, neither conventional cartridge cases filled with powder nor ullage fillers within the cases to reduce the volume of powder would provide both sufficiently low speed and repeatability. We replaced the conventional $14.5 \mathrm{~mm}$ powder breech with a low pressure (and cost) solenoid activated reservoir gas breech as shown in Figures 1 and 2 respectively. We installed a 300 psi fast-acting solenoid. This allowed us to obtain reliably projectile speeds between $195 \mathrm{fps}$ and 735 fps for projectiles ranging in mass from 2.0- to 9.5 grams. However, even a "fast-acting" solenoid is relatively slow. The slow reaction time of the solenoid places an upper bound on projectile speed because the pressure build-up within the gun is limited. We did not need the air breech for higher projectile speeds. For higher projectile speeds in this projectile mass range, we use the ullage filler technique employing conventional small arms propellants. 


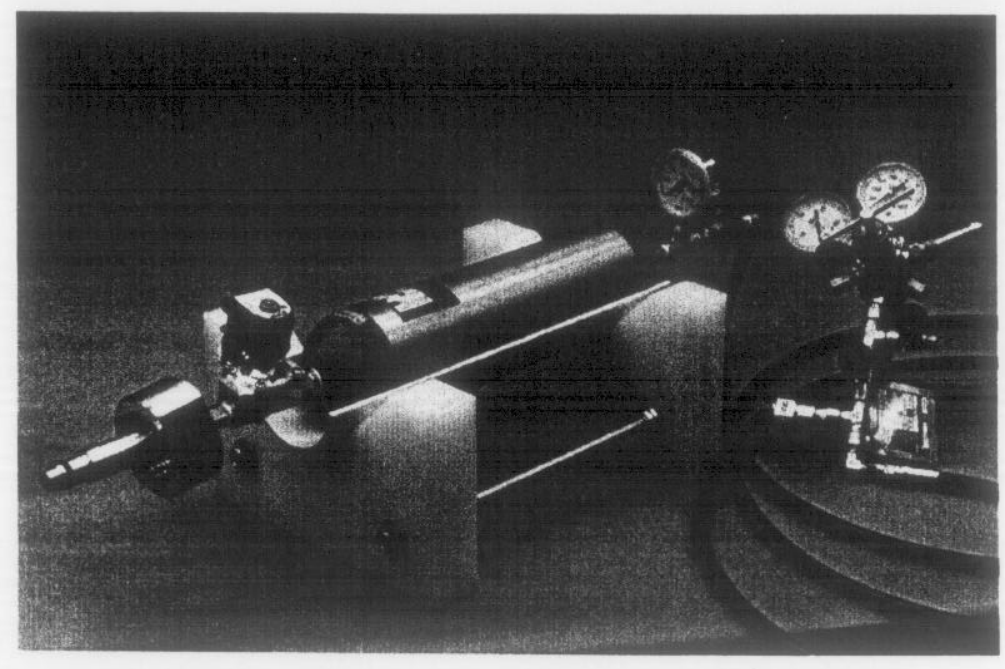

Figure 1. Solenoid Activated Gas Breech 


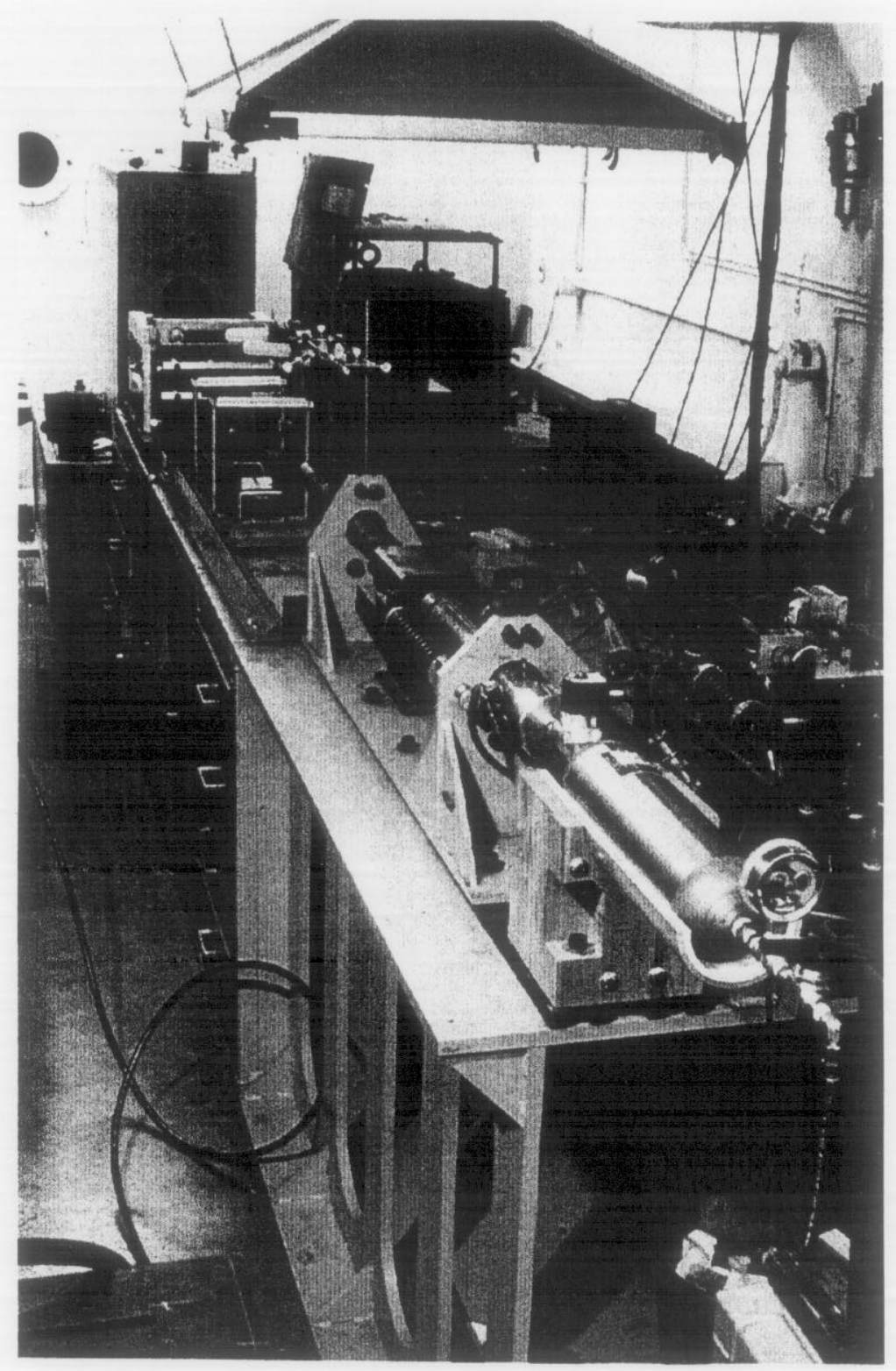

Figure 2. Gas Breech, Launcher, Chronograph, and Projectile Trap

Each projectile is seated in a sabot (carrier) before emplacement within the launcher. The sabot holds the projectile and is the interface between the projectile and the internal surfaces of the launcher. Each sabot was machined from polypropylene in the geometry of a hollow, thin walled right circular cylinder with a concave base. 
Our first experiments used a conventional flash radiography system to determine projectile speed, orientation just before impact, and projectile residual speed and orientation after target perforation. When we used radiography to estimate residual projectile speed and orientation after target perforation, we employed a compact counter chronograph to determine pre-impact projectile speed as shown in Figure 3. We initially tried using foil switch triggers. However, we were concerned that we were disrupting the projectiles before they reached their targets because the projectiles have such small mass. The chronograph system proved to be very reliable and allowed faster production of experiments since we neither had to fabricate foil switches nor had to process additional radiographic film. Once the proper projectile attitude after launch is demonstrated, the changeover to the chronograph system is easy and reliable.

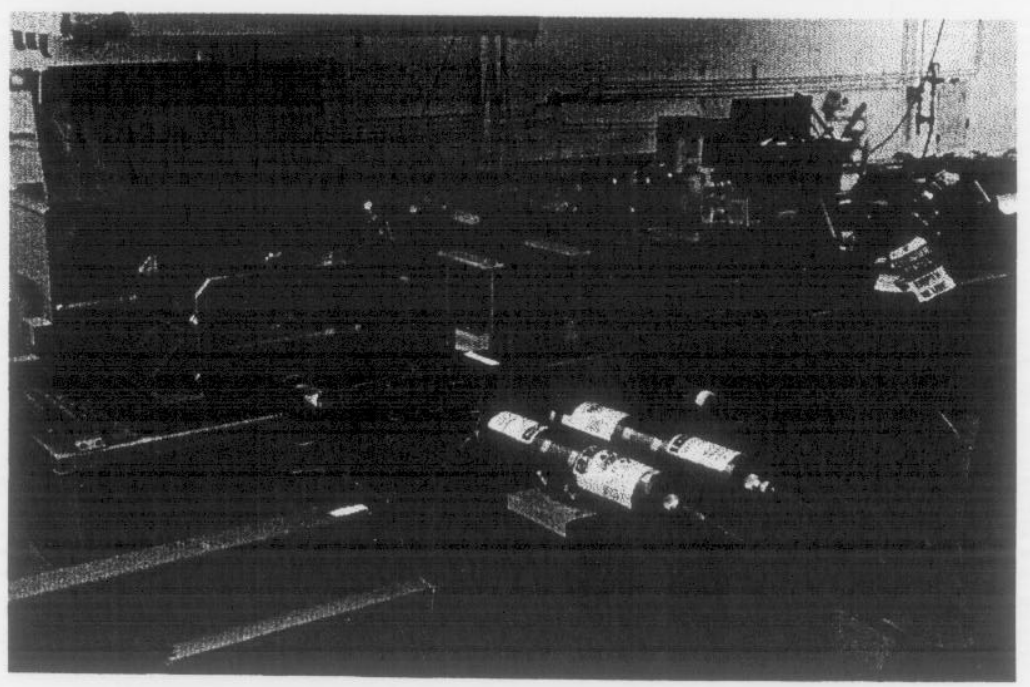

Figure 3. Chronographic and Radiographic Hardware

\section{Experiments}

The first set of full-scale experiments was conducted with a $14.5 \mathrm{~mm}$ air propelled launcher. The object of the experiments was to determine the ballistic limit speed of 6Al-4Valloy titanium, low fineness ratio projectiles centrally impacting 2024-T3 alloy aluminum flat plates and the failure modes of the projectiles and the targets.

Three different projectile geometries were employed for the experiments. The projectiles were machined from 0.50-inch diameter titanium bar stock. The materials specification was MIL-T-9047G Condition A AMS $26 \mathrm{AL}-4 \mathrm{~V}$. The hardness of the titanium was Rockwell C (RC) 37. Chemical analysis of the titanium stock yielded the following percentages of trace and alloying elements (the balance being titanium):
$\mathrm{N}: 0.008$
Fe: 0.1950
C: 0.0165
O2: 0.1600
H: 0.0029
Al: 6.2500
Y: 0.0010
V: 4.1300 
Mechanical properties of the titanium bar stock were reported as:

Tensile Strength (ksi) (longitudinal): Yield Strength (ksi) ( $0.2 \%$ offset):

$\%$ Elongation

$\%$ Reduction in Area
161.2

142.1

15.0

54.8

Three projectiles were employed for the experiments: (1) a fragment simulant projectile (FSP), (2) a right circular cylinder with fineness ratio of $1.0(\mathrm{RCCl})$, and (3) a right circular cylinder with fineness ratio of 0.2 (RCC0.2). Projectile diameter was held constant at 0.50 -inch for all projectiles. Figure 4 displays the geometry of the FSP. FSPs are standardized projectiles used by the military to characterize the impact of "chunky" projectiles against a variety of targets. The RCC1 projectiles were used to determine the sensitivity of ballistic performance to a modest change in nose shape. The lengths of the FSP and RCC1 projectiles were the same. The RCC 0.2 projectiles were chosen to record the effect of a fundamentally onedimensional, non-steady interaction between projectile and target. 

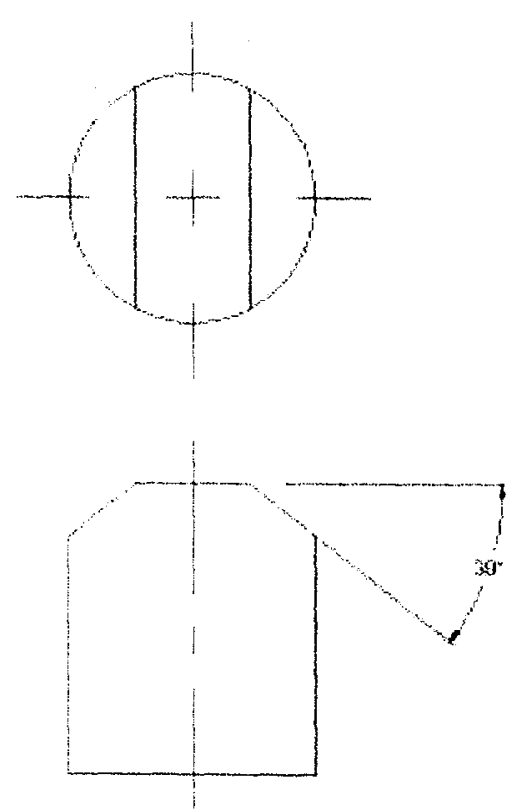
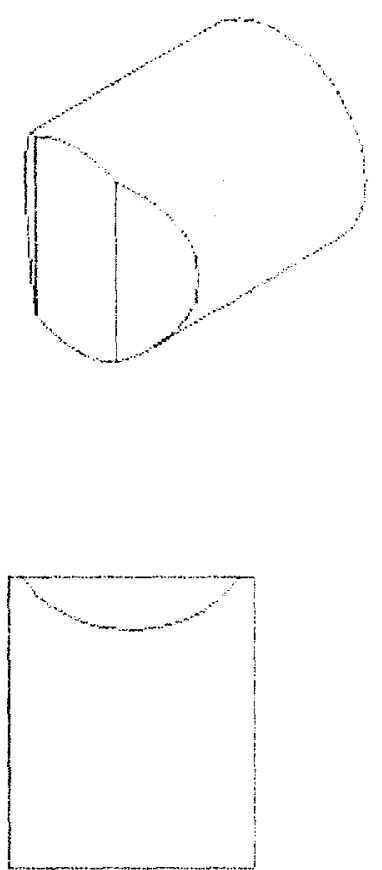

FAA PFLICAM

FFAGMEMT WHILATDF

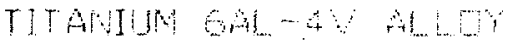
Buture mugen

\section{Figure 4. FSP Geometry}

The target plates were composed of 2024 -T3 alloy aluminum manufactured by Kaiser Aluminum.

Commercial aircraft "skin" is usually composed of the selected aluminum alloy in thickness between 0.05inch and 0.010 -inch. The planform of the plates are 6.0 -inch by 6.0 -inch. Plates of thickness 0.05 -inch, 0.10 -inch, and 0.15 -inch were ballistically evaluated. Chemical analysis of the aluminum plates yielded the following percentages of trace and alloying elements (the balance being aluminum):

$\begin{array}{cc}\text { Si: } 0.08 & \text { Fe: } 0.22 \\ \text { Cr: } 0.016 & \text { Cu: } 4.76 \\ \text { Zn: } 0.07 & \text { Mn:0.65 } \\ \text { Ti: } 0.03 & \underline{\text { Mg: } 1.38} \\ \text { V: } 0.02 & \end{array}$

Mechanical properties of the aluminum plate were reported as:

Tensile Strength (ksi) (longitudinal):

Recorded below are the details of the thirty-eight experiments performed against the 2024-T3 aluminum plate targets. For each experiment, the projectile impacted the target plate with the projectile's velocity vector perpendicular to the flat target plate, i.e. a normal impact. 
Table 1 displays the details of seven ballistic experiments in which the titanium FSPs were launched against the 0.150-inch thick aluminum plate targets. The mass of a typical FSP is 7.93 grams. In many cases, when a projectile perforated an aluminum plate target, we not only recovered the projectile, but also the aluminum "cap" created from the target plate during the process of plate perforation. Over the range of impact speeds for the experiments, we examined the recovered FSP projectiles and observed little or no permanent deformation, i.e. we could have reused the projectiles had we so chosen. In three of the experiments we estimated the speed of the projectile after perforating a target, Vres, using the radiographic technique described above.

\section{Table 1. 0.50" 6Al-4V Titanium FSPs and 0.150" 2024-T3 Aluminum Plate Targets}

\begin{tabular}{llll} 
Experiment \# & Vimpact (fps) & Perforation & Remarks \\
\cline { 3 - 4 } & & & \\
FAA-06 & $900($ Vres $=619)$ & Yes* & Projectile not deformed; target plug failure \\
FAA-07 & 694 & No & Projectile lodged in target \\
FAA-13 & $868($ Vres $=504)$ & Yes* & Aluminum cap recovered \\
FAA-14 & $677($ Vres $=443)$ & Yes* & \\
FAA-33 & 469 & No & \\
FAA-34 & 496 & No & \\
FAA-41 & 583 & No & Deep indentation and cracking \\
* Radiograph of projectile taken after projectile perforated target plate.
\end{tabular}

Table 2 displays the details of ten ballistic experiments in which the titanium RCCls were launched against the 0.150 -inch thick aluminum plate targets. The fineness ratio of the $\mathrm{RCCl}$ is 1.0. The mass of a typical $\mathrm{RCC} 1$ is 8.18 grams. The length of the RCC1 is equal to the length of the FSP. We continued to observe no apparent deformation of recovered RCC1 projectiles. Target perforations were characterized as plug (shear) failures. In two of the experiments, we estimated the speed of the projectile after perforation of the aluminum target plate using the radiographic techniques discussed above.

\section{Table 2. 0.50" 6Al-4V Titanium RCC1s and 0.150" 2024-T3 Aluminum} PlateTargets

\begin{tabular}{llll} 
Experiment \# & Vimpact (fps) & Perforation & Remarks \\
\cline { 2 - 3 } FAA-15 & $999($ Vres=833) & Yes* & \\
FAA-16 & $650($ Vres=295) & Yes* & Target plug failure \\
FAA-19 & 451 & No & Projectile gas launched \\
FAA-28 & 471 & No & \\
FAA-29 & 546 & No & \\
FAA-30 & 588 & No & \\
FAA-31 & 516 & No & \\
FAA-32 & $696(?)$ & Yes & Speed estimated by powder load \\
FAA-37 & 653 & --- & Projectile launch failure \\
FAA-40 & 668 & Yes & Clean target plug failure
\end{tabular}

Table 3 displays the details of eight ballistic experiments in which the titanium FSPs were launched against the 0.100 -inch thick aluminum plate targets. Here, we see the target failure mode to be a tearing (petal) type when a target plate is deeply indented or perforated. In one experiment, we estimated the speed of the projectile after perforation of the aluminum target plate. 
Table 3. 0.50" 6Al-4V Titanium FSPs and 0.100" 2024-T3 Aluminum Plate Targets

Experiment \# Vimpact (fos) Perforation Remarks

$\begin{array}{llll}\text { FAA-08 } & 545 & \text { Yes* } & \begin{array}{l}\text { Target petal failure } \\ \text { Projectile may have pitched ? }\end{array} \\ \text { FAA-09 } & 589 & \text { No } & \\ \text { FAA-10 } & 543(\text { Vres=481) } & \text { Yes* } & \text { Target petal has projectile nose stamp } \\ \text { FAA-11 } & 623 & \text { Yes } & \\ \text { FAA-12 } & 657 & \text { Yes } & \text { Projectile gas launched } \\ \text { FAA-17 } & 416 & \text { No } & \text { Symmetric indentation in target } \\ \text { FAA-18 } & 465 & \text { No } & \text { Deep impression in target with tearing } \\ \text { FAA-35 } & 522 & \text { No } & \end{array}$

Table 4 displays the details of seven ballistic experiments in which the titanium FSPs were launched against the 0.050 -inch thick aluminum plate targets. Here, the target failure mode continues to be tearing (petaling).

Table 4. 0.50" 6Al-4V Titanium FSPs and 0.050" 2024-T3 Aluminum Plate Targets

\section{Experiment \# Vimpact (fps) Perforation Remarks}

$\begin{array}{llll}\text { FAA-20 } & 271 & \text { No } & \text { Projectile nose stamped in target } \\ \text { FAA-21 } & 351 & \text { No } & \text { Target petal attached } \\ \text { FAA-22 } & 367 & \text { No } & \\ \text { FAA-23 } & 424 & \text { Yes } & \\ \text { FAA-36 } & 466 & \text { Yes } & \\ \text { FAA-38 } & 423 & \text { No } & \text { Projectile found ahead of plate } \\ \text { FAA-39 } & 403 & \text { No } & \text { Projectile found ahead of plate }\end{array}$

Table 5 displays the details of six ballistic experiments in which the titanium $R C C 0.2 \mathrm{~s}$ were launched against the 0.050 -inch thick aluminum plate targets. The fineness ratio of the RCC 0.2 is 0.2 . The mass of a typical RCC0.2 is 1.42 grams. Target perforations were characterized as plug (shear) failures.

Table 5. 0.50" 6Al-4V Titanium RCC0.2 and 0.050" 2024-T3 Aluminum Plate Targets

\begin{tabular}{|c|c|c|c|}
\hline Experiment \# & Vimpact (fps) & Perforation & Remarks \\
\hline FAA-42 & 736 & No & Deep indentation in target \\
\hline FAA-43 & 591 & Yes (?) & Projectile highly yawed at target \\
\hline FAA-44 & 593 & Yes (?) & Projectile highly yawed at target \\
\hline FAA-45 & 1223 & Yes & target plug failure - new sabot for projectile \\
\hline FAA -46 & 886 & No & Deep indentation in target \\
\hline FAA -47 & 880 & Yes & plug recovered; late time tearing \\
\hline
\end{tabular}




\section{Failure Modes and Projectile Limit Speeds}

Table 6 below summarizes our estimates of projectile limit speed for each combination of titanium projectile and aluminum target plate discussed above. For the experiments conducted in this series, we did not observe any significant permanent deformation of the recovered projectiles. We could have used the recovered projectiles again.

For the three FSP sets of experiments, projectile limit speed decreases in an almost linear manner with aluminum plate thickness. A simple, one-dimensional model for thin plate shear plug failure by nondeforming projectiles (Ref 1$)$ indicates such a linear relationship. At a plate thickness of 0.150 -inch, the plate failure mode is by shearing. Figures 5 and 6 display the front and rear views of the target plates used in Experiments FAA-14 and FAA-41. The non-deformed, recovered titanium projectiles are displayed along with the aluminum cap (plug) that was sheared from the target plate during impact. The target plate failure is a typical shear failure. In the non-perforated plate (Experiment FAA-41) observe the indentation caused by the chiseled nose of the FSP. For the two thinner target plates, the failure mode was by tearing, i.e. petal failure. Figure 7 displays typical aluminum plates recovered after impact and perforation with petal failures (Experiments FAA-23 and FAA-39 with 0.050-inch thick aluminum plate).

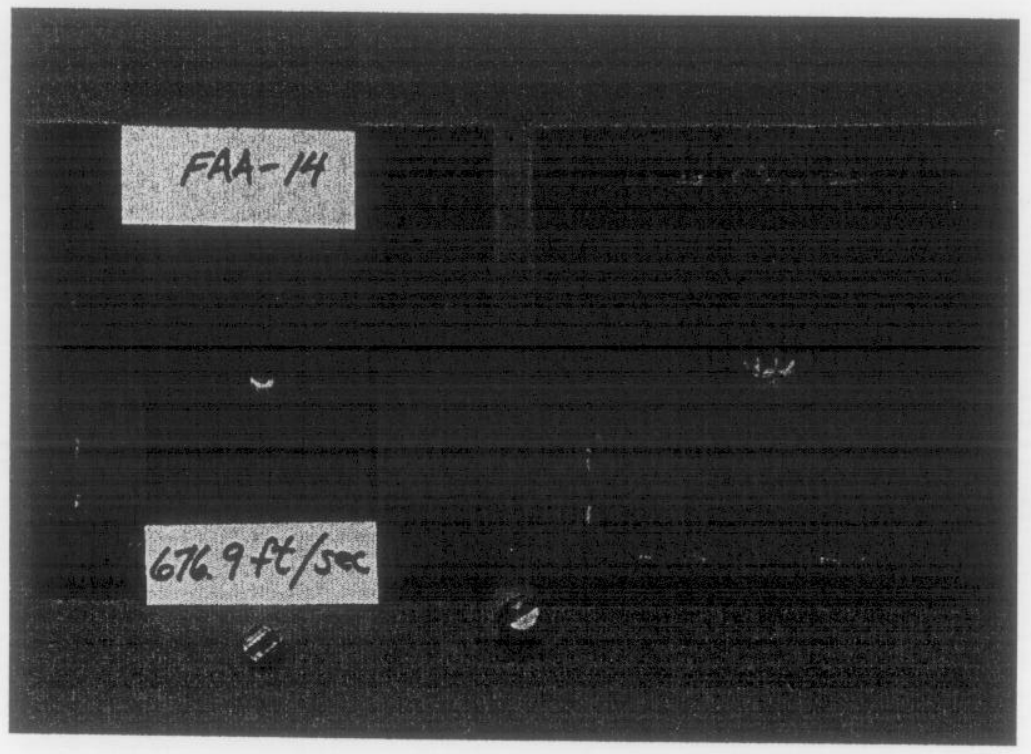

Figure 5. Typical Aluminum Plates - Front Face 


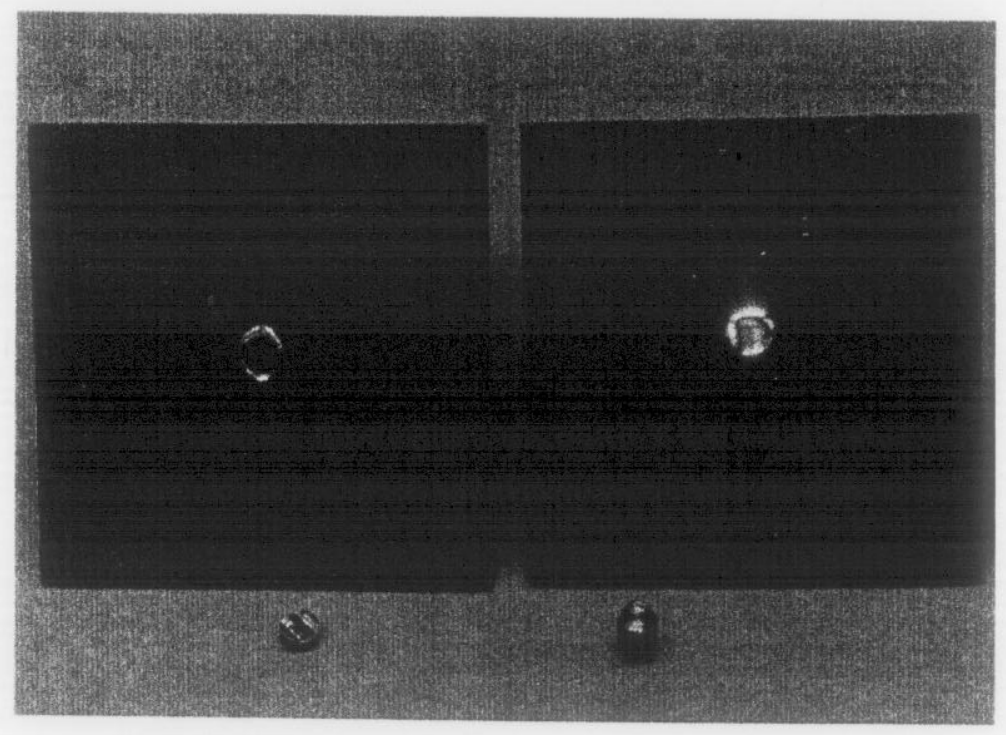

Figure 6. Typical Aluminum Plates (FAA-14 on left) - Rear Face

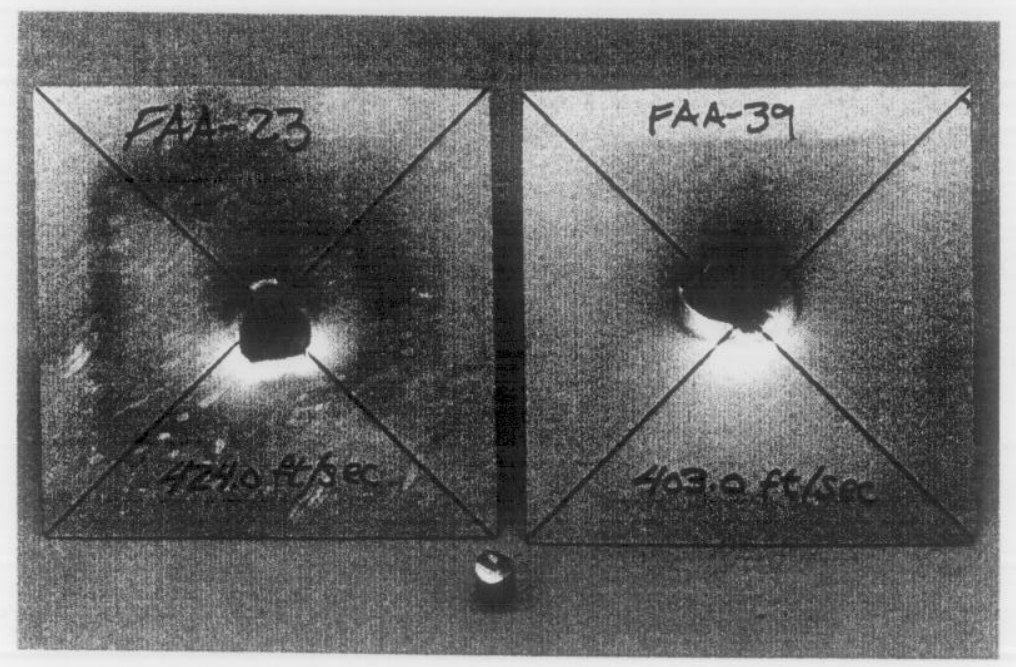

Figure 7. Typical Aluminum Plates with Petal Failures - Front Face

According to Irwin (Ref. 2), there is a critical plate thickness at which the fracture mode of a propagating crack changes from a ductile to a brittle mode. Ductile fracture occurs when plate thickness is below the critical thickness; brittle fracture occurs when plate thickness is above the critical thickness. For 2024 alloy aluminum, we estimate that the critical plate thickness is between 0.135 -inch and 0.325 -inch depending on the values selected for tensile yield stress and critical stress intensity factor. We observe a change in aluminum target plate failure mode due to projectile impact from tearing (petaling) to shearing (plugging) as plate thickness was increased from 0.010 -inch and 0.015 -inch. 
Table 6. Summary of Projectile Ballistic Limit Speeds and Target Failure Modes

$\begin{array}{llll}\text { Projectile } & \text { Target } & \text { Vbl (fps) } & \text { Failure Mode }\end{array}$

Fragment Simulant Projectile(FSP)

$\begin{array}{lll}0.150 " \text { Plate } & 630 \pm 47 & \text { Plug (shear) Failure } \\ \text { 0.100" Plate } & 533 \pm 11 & \text { Petal (tear) Failure } \\ \text { 0.050" Plate } & 414 \pm 11 & \text { Petal (tear) Failure }\end{array}$

Right Circular Cylinder Projectile (RCC1)
0.150 " Plate
$619 \pm 31$
Plug (shear) Failure

Right Circular Cylinder Projectile (RCC0.2)
0.050 " Plate
$883 \pm 3$
Plug (shear) Failure

The RCC1 titanium projectile has a mass about $3.0 \%$ larger than the FSP projectile. The diameter and length of the RCCl projectile are the same as the FSP projectile. The only difference is that the RCC1 projectile has a blunter nose. On the basis of the limit speeds of the two projectiles against the same aluminum plate target (thickness of 0.150 -inch), we conclude that the small increase in projectile nose bluntness has not affected projectile limit speed. The simple shear plug model indicates that a $3.0 \%$ increase in projectile mass lowers projectile limit speed by $1.5 \%$ against the same target. The target plate failure mode is the same for the RCC1 and FSP projectiles-shear plug failure.

The RCC0.2 titanium projectile has a mass about $18 \%$ of that of the FSP projectile. The diameter of the $\mathrm{RCC} 0.2$ projectile is the same as that of the FSP projectile. To insure that the sabot produced an insignificant impact effect on the aluminum targets, we machined the sabots from polyurethane foam (specific gravity of $0.2 \mathrm{gm} / \mathrm{cc}$ ). Sabot geometry is a hollow right circular cylinder with fineness ratio of one and is such that a projectile front face is flush with a sabot face.

Using the simple plug model, we expect that a change in fineness ratio from 1.0 to 0.2 would increase the limit speed by a factor of 2.35. Had the failure mode of the titanium FSP against the 0.050 -inch aluminum target plate been a shear failure, we would have expected the RCC 0.2 projectile limit speed to have been about $973 \mathrm{fps}$ ( $414 \mathrm{fps} \times 2.35$ ). However, the 0.050 -inch aluminum plate failure mode was a petal failure. This implies that the 973-fps estimate is only an upper bound. For a selected projectile and target which undergoes transition from plug to petal failure as target plate thickness is decreased, it appears that a smaller percentage of the projectile's kinetic energy at impact is transferred to the plate when the plate undergoes a shear (plug) mode failure than when it undergoes a petal (tear) mode failure (Ref 1 ). This implies that projectile limit speed could be lower for a shear failure than for a petal failure all else held constant (i.c. if the plate had a choice of failure mode). Again, the recovered RCC 0.2 projectiles were observed to have not deformed during the impact events. 


\section{Titanium Projectiles and Plate Targets}

\section{Launch and Measurement Techniques}

The experiments required the launch of high fineness ratio massive projectiles. These were the largest projectiles we have launched from our $14.5 \mathrm{~mm}$ single stage, powder launcher. We tried launching the projectiles with a conventional cartridge case. However, even though the projectiles were massive, the case volume was too large to produce reliable, repeatable projectile speeds under $1,000 \mathrm{fps}$.

We returned to the use of an ullage filler. An ullage filler is a solid cartridge case that is machined down the centerline to the gun bore diameter with a smaller diameter powder chamber at its base. This produces a much smaller ratio of powder to chamber volume and consequently better utilizes the burning characteristics of powder. Employing the ullage filler approach and the appropriate powder, we produced repeatable projectile speeds of $300 \mathrm{fps}$ to $1500 \mathrm{fps}$.

The launch of very long projectiles proved to be damaging to our counter chronograph because the projectiles tended to rebound off the target face on non-perforating impacts. In addition, a projectile of fineness ratio of twenty had a length that exceeded the distance between the light sensors of the chronograph producing unreliable (false) speed-readings. Therefore, in order to measure projectile speed reliably, we employed a pair of foil switches spaced a known distance apart and connected to an interval counter. Each foil switch consists of two 0.002 -inch thick copper foils separated and protected by a 0.001 inch thick layer of Mylar. The foils are connected to a co-axial cable and charged with a $150 \mathrm{v}$ bias voltage. When a projectile perforates the foils, the foil edges make contact and short the circuit producing a "start" or "stop" pulse for the counter. The foil switches have proven again to be rugged, reliable, and accurate. All projectile speeds for the second series of experiments were determined from the foil switches.

\section{Experiments}

The second set of one-third scale experiments was conducted with a $14.5 \mathrm{~mm}$ powder launcher. The object of these experiments was to determine the ballistic limit speed of 6Al-4Valloy titanium high fineness ratio projectiles centrally impacting $6 \mathrm{Al}-4 \mathrm{~V}$ alloy titanium flat plates and the failure modes of the projectiles and the target. A full-scale titanium target plate is considered to be 0.75 - inch thick, i.e. the thickness of a containment ring.

The titanium projectiles for the second series were 0.58 -inch in diameter and were shaped as right circular cylinders. Three projectile lengths were chosen corresponding to projectile fineness ratios of 10,15 , and 20 . Projectile mass was 112 grams, 168 grams, and 226 grams respectively. The projectiles were machined from 0.750-inch diameter titanium bar stock. The materials specification was MIL-T-9047G COND A AM $26 \mathrm{AL}-4 \mathrm{~V}$. Chemical analysis of the titanium stock yielded the following percentages of trace and alloying elements (the balance being titanium):

$\begin{array}{ll}\text { N: } 0.0115 & \text { Fe: } 0.1650 \\ \text { C: } 0.0135 & \text { O2: } 0.1750 \\ \text { H: } 0.0032 & \text { Al: } 6.2400 \\ \text { Y: } 0.0010 & \text { V: } 4.1100\end{array}$


Mechanical properties of the titanium bar stock were reported as:

$\begin{array}{lr}\text { Tensile Strength (ksi) (longitudinal): } & 152.3 \\ \text { Yield Strength (ksi) (0.2\% offset): } & 141.9 \\ \text { \% Elongation } & 16.5 \\ \text { \% Reduction in Area } & 44.3\end{array}$

The target plates were composed of $6 \mathrm{Al}-4 \mathrm{~V}$-alloy titanium. Some commercial aircraft jet engine containment rings are composed of titanium. The dimensions of the target plates were 6.0 -inch by 6.0 -inch $x$ 0.25-inch. The materials specification was MIL-T-9046J AM 2 AB-1 6AL-4V (AMS 4911 H 6Al-4V). Chemical analysis of the titanium plate yielded the following percentages of trace and alloying elements (the balance being titanium):

$\begin{array}{ll}\text { N: } 0.0090 & \text { Fe: } 0.1650 \\ \text { C: } 0.0150 & \text { O2: } 0.1800 \\ \text { H: } 0.0045 & \text { Al: } 6.2200 \\ \text { Y: }<0.0010 & \text { V: } 4.0450\end{array}$

Mechanical properties of the titanium plate were reported as:

$\begin{array}{ll}\text { Tensile Strength (ksi) } & \\ \text { longitudinal: } & 138.0 \\ \text { transverse: } & 159.0 \\ \text { Yield Strength (ksi) (0.2\% offset) } & \\ \quad \text { longitudinal: } & 141.9 \\ \quad \text { transverse } & 147.0 \\ \text { \% Elongation } & 13.5 \\ \text { \% Reduction in Area } & 23.5\end{array}$

Recorded below are the details of the ten experiments performed against the $6 \mathrm{Al}-4 \mathrm{~V}$ alloy titanium plate targets. For each experiment, the projectile impacted the target plate with the projectile's velocity vector perpendicular to the flat target plate, i.e. a normal impact.

Table 7 displays the details of ten ballistic experiments in which the titanium projectiles were launched against the 0.250 -inch thick titanium plate targets. For the three experiments conducted with projectiles of fineness ratio of 20, the target was perforated during each experiment. This was also the case for the experiments with projectiles of fineness ratio of 10 . For the experiments with projectiles of fineness ratio of 15 , we were able to estimate the limit speed. As described above, we used foil switches to determine the velocity of a projectile before impact with a target. Here, the projectiles are relatively massive (compared to the foil switch triggers). We were not concerned about projectile damage or disruption upon encounter with a foil switch. 
Table 7. 0.58” 6Al-4V Titanium Projectiles and 6Al-4V Titanium Plate Targets

\begin{tabular}{|c|c|c|c|c|}
\hline $\begin{array}{l}\text { Projectile } \\
\text { L/D }\end{array}$ & Experiment\# & Vimpact (fos) & Perforation & Remarks \\
\hline 20 & $\begin{array}{l}\text { FAA-51 } \\
\text { FAA-55 } \\
\text { FAA-56 }\end{array}$ & $\begin{array}{r}1427 \\
817 \\
571\end{array}$ & $\begin{array}{l}\text { Yes } \\
\text { Yes } \\
\text { Yes }\end{array}$ & $\begin{array}{l}\text { RP }(0.560 \text { inch }) * \\
R P(0.410 \text { inch }) \\
R P(0.060 \text { inch })\end{array}$ \\
\hline 15 & $\begin{array}{l}\text { FAA-57 } \\
\text { FAA-58 } \\
\text { FAA-59 }\end{array}$ & $\begin{array}{l}559 \\
377 \\
454\end{array}$ & $\begin{array}{l}\text { Yes } \\
\text { No } \\
\text { No }\end{array}$ & $\begin{array}{l}\text { RP }(0.045 \text { inch })^{* * *} \\
\text { Slight target plate bulge } \\
\text { Substantial target bulge }\end{array}$ \\
\hline 10 & $\begin{array}{l}\text { FAA-52 } \\
\text { FAA-53 } \\
\text { FAA-54 } \\
\text { FAA-60 }\end{array}$ & $\begin{array}{c}1262 \\
1029 ? \\
795 \\
608\end{array}$ & $\begin{array}{l}\text { Yes } \\
\text { Yes } \\
\text { Yes } \\
\text { Yes }\end{array}$ & $\begin{array}{l}\text { RP }(0.350 \text { inch }) \\
\text { RP }(0.150 \text { inch })^{* *} \\
\text { No result at witness block } \\
\text { RP }(0.000 \text { inch })\end{array}$ \\
\hline
\end{tabular}

* RP is the residual penetration into a 6 inch $\times 6$ inch $\times 4$ inch thick 6061-T6 alloy aluminum witness block.

** The foil switch triggered late. $1029 \mathrm{fps}$ is a speed estimate from the mass/load launcher data.

*** Two crescent shaped nicks in the witness block with maximum depth of penetration of 0.045 inch.

\section{Failure Modes and Projectiles Limit Speeds}

Table 8 below summarizes our estimates of projectile limit speed and lower bound for projectile limit speed for the titanium projectiles and the titanium target plate discussed above. For the experiments conducted in this series, projectile damage due to target impact was slight at the best. One could observe visually a very slight "mushrooming" of the blunt projectile nose when examining the projectiles after the experiments. It would be a good approximation to assume that the projectiles penetrated/perforated the targets as "rigid bodies"”

Table 8. Summary of Projectile Ballistic Limit Speeds and Target Failure Modes

$\begin{array}{lll}\text { Projectile } & \text { Vbl (fps) } & \text { Failure Mode } \\ \text { Fineness Ratio } & \end{array}$

20

$<571$

Plug (shear) Failure

15

$507 \pm 52$

Plug(shear) Failure

10

$<608$

Plug(shear) Failure 
The simple, one-dimensional model for thin plate shear plug failure by non-deforming projectiles (Ref 1) indicates that if the limit speed for the projectile with fineness ratio of 15 is about $480 \mathrm{fps}$, then the corresponding limit speeds of the projectiles with fineness ratios of 10 and 20 would be about $590 \mathrm{fps}$ and 420 fps respectively. These estimates are consistent with the ballistic data above.

For each projectile, the titanium plate failure mode is by plugging (shear failure). We recovered many of the titanium "plugs" after the experiments. Plug diameter is just slightly larger than projectile diameter. Recovered titanium projectiles are almost without any observable damage. The target plate failure is a typical shear failure.

\section{Closing Remarks and Conclusions}

We conducted two sets of fundamental experiments in penetration mechanics in the LLNL Terminal Ballistics Laboratory of the Physics Directorate. The first set of full-scale experiments was conducted with a $14.5 \mathrm{~mm}$ air propelled launcher. The object of the experiments was to determine the ballistic limit speed of $6 \mathrm{Al}-4 \mathrm{~V}$-alloy titanium, low fineness ratio projectiles centrally impacting 2024-T3 alloy aluminum flat plates and the failure modes of the projectiles and the target.

During the course of the experiments, we did not observe any significant permanent deformation of the recovered projectiles. We could have used the recovered projectiles again.

At a plate thickness of 0.150 -inch, the plate failure mode is shearing, i.e. a plug failure. For the two thinner target plates, thickness of 0.010 -inch and 0.050 -inch, the plate failure mode is tearing, i.e. petal failure. The critical plate thickness for the failure mode transition from tearing to shearing due to projectile impact is consistent with the critical plate thickness associated with the fracture mode transition of a propagating crack, i.e. ductile to brittle fracture. For 2024 alloy aluminum, we estimate that the critical plate thickness for the transition in crack fracture mode is between 0.135 -inch and 0.325 -inch depending on the values selected for tensile yield stress and critical stress intensity factor. We observe a change in aluminum target plate impact failure mode from petaling to plugging as plate thickness increases from 0.010 -inch and 0.015 inch.

The second set of one-third scale experiments was conducted with a $14.5 \mathrm{~mm}$ powder launcher. The object of these experiments was to determine the ballistic limit speed of $6 \mathrm{Al}-4 \mathrm{Valloy}$ titanium high fineness ratio projectiles centrally impacting $6 \mathrm{Al}-4 \mathrm{~V}$ alloy titanium flat plates and the failure modes of the projectiles and the target

For the experiments, we observed that projectile damage due to target impact was slight at the best. One could observe visually a very slight "mushrooming" of the blunt projectile nose when examining the projectiles after the experiments. It would be a good approximation to assume that the projectiles penetrated/perforated the targets as "rigid bodies""

For each of the three projectiles evaluated, the titanium target plates failed by plugging (shear failure). In many cases, we recovered projectiles almost without any observable damage, titanium "caps" that were sheared out of the target plate ahead of the penetrating projectile, and target plates with circular holes in their centers just slightly larger than the projectile diameter. 


\section{References}

1. "Terminal Ballistic Experiments for the Development of Turbine Engine Blade Containment Technology" by Raymond P. Gogolewski and Bruce J. Cunningham, Lawrence Livermore National Laboratory, UCRL-ID-120930, January 25, 1995.

2. "Fracture Mode Transition for a Crack Traversing a Plate," G. R. Irwin, J. Basic Engineering, Transactions of the ASME, June 1960. 